\title{
ALGUMAS OBSERVAÇÕES ACERCA DA FORMAÇÃO DOS VERBOS ÁRABE E HEBRAICO
}

\section{SOME REMARKS ON THE FORMATION OF VERBS IN ARABIC AND HEBREW}

Suely Ferreira Lima*

Resumo: Um dos traços característicos das línguas semítica é a estrutura morfológica cujo léxico é formado, majoritariamente, a partir de três consoantes chamadas radicais, responsáveis por encerrarem o significado básico da palavra. Por fazerem parte dessa mesma família de línguas, o árabe e o hebraico partilham, além do que expusemos acima, de muitas características comuns. De uma maneira geral, este estudo procura observar as formas que o verbo simples, hebraico e árabe, pode tomar ao lhe serem aplicados certos padrões para expressar as diversas formas/grau/vozes. Observamos, nos exemplos das duas línguas estudadas, que a formação dos verbos, a partir da raiz trilítera simples, se dá por meio de processos morfológicos extremamente previsíveis e regulares, no entanto, não se pode dizer o mesmo dos valores semânticos advindos dessas construções, que em várias ocasiões se apresentam como um desafio para uma classificação eficaz. Apesar de vários autores ocidentais observarem em seus trabalhos o quanto estes padrões auxiliam na obtenção de vocabulário, os estudos modernos do hebraico e do árabe têm mostrado o quanto eles podem ser complexos.

Palavras-chave: Morfologia. Verbo árabe. Verbo hebraico. Binyanim. Mazīd.

Abstract: One of the defining traits of the semitic languages is their morphological structure whose lexicon is formed, mostly, from three consonants called "consonantal roots" which convey a basic understanding of a word. Being part of the same linguistic family, Hebrew and Arabic share more than just the aforementioned feature. This study seeks to observe the diferent forms which simple verbs, in Hebrew and Arabic, can take after applying certain patterns in order to express the diverse forms/degree/voices. We observed, in the examples of both languages, that the formation of verbs, based on the simple triliteral root, takes place through highly predictable and regular morphological processes, however, the same can not be said about the semantic values sprung from these constructs, which prove themselves diffucult to classify effectively. Despite several western authors noting in their works how these patterns aid in the creation of vocabulary, recent studies of Hebrew and Arabic show how complex they can be.

\footnotetext{
* Suely Ferreira Lima é professora do Setor de Estudos Árabes da Faculdade de Letras da Universidade Federal do Rio de Janeiro, Doutora pelo programa de Pós-graduação em Estudos Judaicos e Árabes do Departamento de Letras Orientais da Faculdade de Filosofia, Letras e Ciências Humanas da Universidade de São Paulo e Mestre em Letras Vernáculas pelo Programa de Pós-graduação em Letras Vernáculas da Faculdade de Letras da Universidade Federal do Rio de Janeiro. Email: <suelyma@letras.ufrj.br〉.
} 
Keywords: Morphology. Arabic verb. Hebrew verb. Binyanim. Mazīd.

\section{Introdução}

Ao estudarmos as línguas semíticas, não podemos deixar de mencionar seu traço mais característico: a estrutura de formação de palavras. Seu léxico é formado, majoritariamente, a partir de três consoantes chamadas radicais que encerram o significado básico da palavra. Então, por exemplo, para se expressar o conceito de matar, em ambas as línguas, a sequência consonantal $/ q /$ - /t/ - /l/ é usada para expressar a ideia; na qual $<\mathrm{q}>$, seria a primeira letra radical, seguida da segunda, $\langle\mathrm{t}\rangle^{1}$, e, por fim, da terceira letra $<1>$. A disposição destes grafemas é fundamental à integridade da raiz, e a alteração desta ordem implica mudança total de significado.

Apesar do caráter triconsonântico majoritário dessas línguas, palavras de duas, quatro e cinco consoantes, estas mais raras, também existem. Segundo Hetzron (1977, p.155.), sincronicamente, as raízes hebraicas biconsonatais seriam alomorfes de tricosonantais, e, diacronicamente, indícios de uma época muito antiga na qual verbos biconsonantais eram comuns, e que, com o tempo, foram "triconsonantizados", já que não é incomum encontrar alternância vocálica entre duas palavras de origem biconsonantal.

Quanto ao árabe, Ryding (2005, p. 47) refere que raízes com quatro ou cinco consoantes podem ser empréstimos de outras línguas; algumas fazem parte do léxico árabe já há centenas de anos, e outras são recentes, como as consoantes do verbo telefonar $/ t /-/ / / / f /-/ n / /$ talfana/.

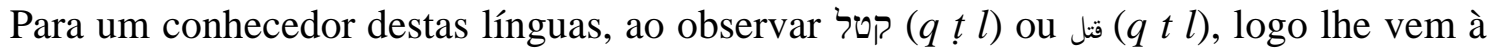
mente a noção de “matar", mas a raiz é apenas uma ideia virtual, não uma palavra. Para tornarse tal, é necessário que se lhe adicionem alguns elementos como outra consoante, vogal longa, vogal breve, dobramento de consoantes que darão à ideia virtual diferentes significados. Assim, para se obter o verbo matar, é necessário, no caso do hebraico, o acréscimo das vogais qāmas à

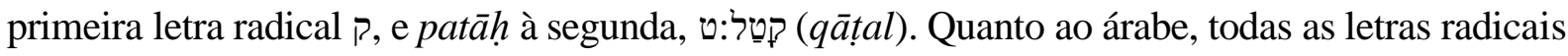
devem ter sobrepostas a vogal fatha para fechar as três sílabas da raiz: ‘َّ (qatala), que significará "ele matou".

Por fazerem parte da mesma família de línguas - a semítica -, o árabe e o hebraico partilham, além do que pudemos observar acima, muitas características comuns. De uma

\footnotetext{
${ }^{1}$ Esta raiz foi escolhida por existir, tanto no árabe quanto no hebraico, porém, a consoante medial na segunda língua é enfática /ț/.
} 
maneira geral, este artigo pretende observar as formas que o verbo simples, hebraico e árabe, pode tomar ao lhe serem aplicados certos padrões para expressar as diversas formas/grau/vozes. Não foi nosso propósito especificar as alterações consonantais e vocálicas sofridas pelas raízes ao longo das diversas flexões diante de certas consoantes: guturais, letras fracas e outras, mas apenas identificar estes elementos e quais os possíveis valores semânticos que poderiam agregar à ideia primitiva da raiz, para, então, se fazer um estudo contrastivo entre as línguas árabe e hebraica.

\section{Qal e facala: o verbo simples}

A forma mais simples/pura dos verbos destas línguas se encontra na terceira pessoa do

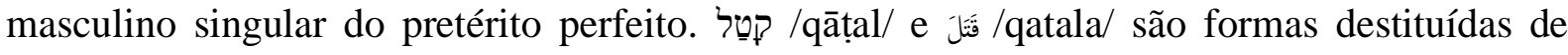
quaisquer outros elementos mórficos que não sejam as letras radicais e seus movimentos vocálicos. A ausência de outros elementos mórficos lhes dá a tradução ele matou.

Por ser simples/pura esta é a forma sob a qual se dá a entrada dos verbos/raízes nos dicionários tradicionais árabes e hebraicos, uma vez que o nome deverbal, ou seja, o que se traduz pelo infinitivo impessoal em português, pode estar acrescido de algum elemento mórfico.

Os gramáticos do hebraico denominaram esta forma pura como Qal, que significa "ele é/foi leve".

Qal: é a mais comum das conjugações na qual a maioria dos verbos tem o seu significado básico. Por isso, é chamada de conjugação "Básica", por vezes abreviada por "B". Algumas gramáticas empregam a designação G, do termo Grundstamm das gramáticas alemães, que significa tronco/sistema básico. (BARTELT, 2006)

Em árabe esta forma primitiva recebe a denominação de mujarrad (na definição de Corriente, 'privado', ‘despojado', ‘desnudo', 'livre'. 'separado', ‘puro', ‘simples’), isto é, livre de prefixos ou sufixos. Cowan refere que:

Quando os árabes começaram a ensinar sua língua depois da expansão

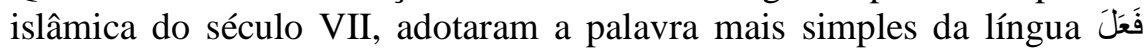

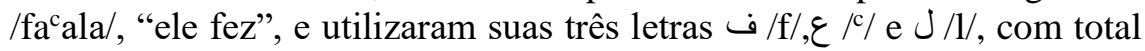
independência da ideia de "fazer", para descrever os diferentes modelos de palavras que eles constataram como existentes. (COWAN, 2006, p. 33) 
Em ambas as línguas, os verbos na forma $\mathrm{fa}^{\mathrm{c}} \mathrm{ala} / \mathrm{qal}$ indicam uma ideia primitiva na voz ativa.

Regra geral, a forma da terceira pessoa do masculino singular do perfeito Qal do verbo normalmente tem três consoantes acompanhadas de duas vogais, de modo a formar uma palavra bissilábica. O acento cai na segunda sílaba. A primeira sílaba é aberta e tem sempre um qameș como vogal. A segunda sílaba é fechada, a não ser quando terminar em $\boldsymbol{N}$ ou $\mathrm{n}$. Quando for fechada, ela tem um patah por vogal. Quando for aberta, ou seja, quando terminar em ou o patah é alongado, transformando-se em qameș. (KELLEY, 1998, p. 109.)

No entanto, esta regra não é absoluta. As línguas semíticas apresentam muitos verbos que em português se traduzem por uma expressão formada com os verbos ser, estar, ter mais um adjetivo ou advérbio, do tipo ser bom, ser grande, estar bem... e, em hebraico, alguns desses

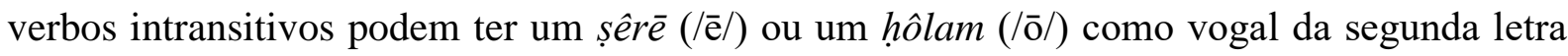
radical. Devem-se mencionar, também, os verbos monossilábicos hebraicos que, originalmente, tinham um yôd ou $w \bar{a} w$ como segunda letra radical, e que, com o passar do tempo, se contraíram com a vogal precedente tornando-se uma vogal longa.

Em árabe, o padrão vocálico do verbo simples na terceira pessoa do singular do perfeito tem sempre fatḥa /a/ sobre a primeira letra radical; porém, como no hebraico, a vogal de segunda letra radical pode ser qualquer uma das três vogais do sistema vocálico arábico: fatḥa /a/, kasra /i/, ou damma /u/. Diferente do verbo hebraico, que é dissilábico, o verbo no árabe clássico sempre terá a vogal fatha /a/, formando, assim, uma palavra trissilábica: $f a{ }^{c} a-l a l f a-{ }^{c} i-$ lalfa-cu-la.

Geralmente, o padrão $a$ - $a$ denota uma ação transitiva ou intransitiva, praticada por um sujeito agente; o padrão $a-i$, teria uma série de significados associados a ele, tornando sua fixação um tanto complexa; já o padrão $a$ - $u$, nas palavras de Holes (2004:101): “é sempre intransitivo e denota posse ou aquisição de uma qualidade que é permanente: hasuna'ser/tornarse bom, bonito', qabuha 'ser/tornar-se feio', sagiura 'ser/tornar-se pequeno, jovem', kabura 'ser/tornar-se largo, grande, velho'.” (HOLES, 2004, p. 101)

\footnotetext{
2 “... is always intransitive and denotes the possession or acquisition of quality that is permanent: $\mathrm{HaSuN}$ 'be/become good, beautiful', QaBuH 'be/become ugly', SaĠur 'be/become small, young', KaBuR 'be/become large, great, old'." (HOLES, 2004, p. 101)
} 


\section{Binyanim}

Além da forma simples Qal, a língua hebraica apresenta, nas palavras de Hetzron (1997, p. 158 e159):

um sistema elaborado de padrões morfológicos (Hebraico medieval e moderno binyanim construções, troncos verbais ou classes derivacionais) usados, em grande parte, para derivar verbos de outros mais básicos. Assim, uma raiz pode gerar uma série de verbos morfologicamente distintos referentes às atividades relacionadas. ${ }^{3}$

Essas formas são em número de sete, incluída a simples, e são construídas a partir da forma Qal de um dado verbo, mediante o uso de prefixos, alterações vocálicas e dobramento de letras, onde "cada uma delas representa um aspecto diferente do significado primário do verbo". ${ }^{4}$

A denominação hebraica dessas formas, binyanim, não encontra consenso para sua tradução, e termos como conjugações, padrões, troncos, graus e a própria palavra hebraica binyanim são encontrados em diversos trabalhos versando sobre o assunto. A denominação mais comum encontrada nas gramáticas atuais, segundo Lambdin (2003, p. 218), é conjugação. Yates argumenta que "É difícil achar um nome apropriado para esta série de formas, as quais dificilmente podem ser chamadas conjugações, modos ou vozes. Será melhor falar delas como raízes". 5

Os sete binyanim seguem uma ordem apresentada, geralmente, pelas gramáticas

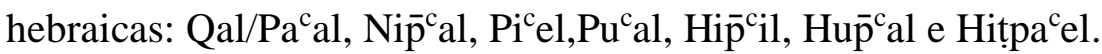

De acordo com Chomsky (1945, p. 293), o paradigma $\bar{p}^{c} 1$ פעל foi emprestado do árabe $\left(f^{c} l\right)$, como modelo para as diversas possibilidades de construção dos verbos hebraicos, mas teve de ser abandonado por ter como segunda letra radical uma consoante gutural, fonema este que não pode ser dobrado como requerem as construções $\mathrm{Pi}^{\mathrm{c}} \mathrm{el}, \mathrm{Pu}^{\mathrm{c}}$ al e Hițpa ${ }^{\mathrm{c}} \mathrm{el}$. Apesar de ter sido abandonado como paradigma para ilustrar as possibilidades de flexão das raízes, os radicais

\footnotetext{
3 “... an elaborate system of morphological patterns (Medieval and Modern Hebrew 'buildings, verbal stems or derivational classes') used, for most part, to derive verbs from otrher, more basic, verbs. Thus, one root can generate a number of morphologically distinct verbs referring to related activities". (HETZRON, 1997, p. 158 e159)

4 “...cada una de las cuales representa un aspecto diferente del significado primário del verbo.” (YATES, 1984, p. 79)

${ }^{5}$ Es difícil hallar un nombre apropriado para esta serie de formas, las cuales dificilmente pueden ser llamadas conjugaciones, modos o voces. Será major hablar de ellas como raices." (YATES, idem)
} 


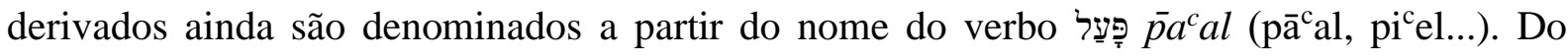
mesmo modo, a posição das letras radicais nas palavras hebraicas ainda são citadas por muitos gramáticos de acordo com a ordem da raiz $\bar{p}^{c} l$. Assim, no verbo qațal, a letra $\langle q\rangle$ ocupa a primeira posição p $\overline{\mathrm{e}}^{\mathrm{\prime}} ;<\mathrm{t}>$ corresponde à posição da letra ${ }^{\mathrm{c}} \mathrm{ayn} ; \mathrm{e}<\mathrm{l}>$ é a letra da posição do lāmed.

Com o abandono da forma $\bar{p}^{c}$, a forma verbal que passou a ser usada para representar os paradigmas dessas raízes foi קטל $q t^{6}$, um verbo comum a outras línguas semíticas, que possui todas as letras fortes, e o sentido geral dos vários binyanim podem ser ilustrados por este verbo.

\subsection{Pācal}

$\mathrm{Pa} \overline{\mathrm{a}}^{\mathrm{c}} \mathrm{al}$ é a forma simples ativa, correspondente à Qal. Sua marca característica é a ausência de qualquer elemento mórfico além das letras radicais e seus padrões vocálicos. Como já vimos anteriormente, por ser a forma Básica, é também conhecida como a forma "B", ou "G" do termo alemão Grundstamm: qāṭal - "ele matou”.

\subsection{Nip̄al}

$\mathrm{Nip}^{-\mathrm{c}}$ al é caracterizado por um elemento $n$-נ prefixado à raiz que expressa a sua noção de reflexividade. Também é conhecido como conjugação "N": niqtal - "ele se matou".

\section{Valores semânticos:}

a) É reflexivo da forma simples: "guardar-se”, "vingar-se", “vender-se”, embora alguns verbos nip ${ }^{\mathrm{c}}$ al não existam na forma Qal: "brigar, "esconder-se”, “adormecer”;

b) Alguns verbos têm um significado reflexivo e passivo ao mesmo tempo: "esconderse/ser escondido", "redimir-se/ser redimido";

c) Em alguns casos, o significado é o de permitir que algo aconteça a si mesmo, geralmente com uma noção de ação eficaz: "permitir-se ser convidado" = "responder" (falando de Deus); "permitir-se ser castigado" = "castigar-se"7;

d) Voz média passiva: "Perguntar-se";

\footnotetext{
${ }^{6}$ Joüon e Muraoka (1993, p. 125) apontam que este verbo não é muito comum em hebraico e que a forma mais usada para expressar ele matou seria הרג, porém foi escolhido $q$-t-l por suas letras fortes e por ser comum em aramaico e árabe, embora, nesta última, a letra é não-enfática.

${ }^{7}$ JOÜON E MURAOKA, 1993, p. 150, 151.
} 
e) Alguns verbos apresentam um sentido de reciprocidade, consultar um ao outro: “deliberar", "encontrar um com o outro", "lutar", "conversar com";

f) Embora mais raramente, alguns verbos deste padrão são derivados de nomes: "profetizar" (de profeta).

\subsection{Picel}

Segundo Joüon-Muraoka (1993, p. 151), das conjugações hebraicas, $\mathrm{Pi}^{\mathrm{c}}$ el é a forma mais imprecisa e difícil de se classificar.

[...] a questão sobre como a função de $\mathrm{Pi}^{\mathrm{c} e} \mathrm{el}$ em relação às outras conjugações, principalmente Qal, deve ser definida, ainda continua um dos maiores desafios face ao hebraico e à linguística semítica. No atual estado de nosso conhecimento, podemos apenas apontar um número de categorias de significados bastante distintos, no qual alguns verbos parecem se encaixar. Outros, um número desconfortavelmente grande, ainda carece de tal classificação. ${ }^{8}$

Os autores consideram que apenas se pode afirmar que é a forma ativa correspondente ao passivo $\mathrm{Pu}^{\mathrm{c}}$ al, e ao reflexivo Hiṭpa ${ }^{\mathrm{c}}$ el. Segundo Lambdin, já que "nem sempre a raiz de um verbo $\mathrm{Pi}^{\mathrm{c}}$ el existe na forma Qal, muitas vezes é difícil definir o significado do $\mathrm{Pi}^{\mathrm{c}} \mathrm{el}$ por meio de comparação direta",9.

A característica formal mais proeminente de $\mathrm{Pi}{ }^{\mathrm{c}}$ el é a duplicação da segunda letra do radical, e tradicionalmente tem sido considerada uma forma de significado intensivo ${ }^{10}$. Por causa da duplicação do radical, também é chamada de conjugação "D”: qițtel - "trucidar", "massacrar".

\section{Valores semânticos:}

a) Para Lambdin (2003, p. 237), a aparência de intensidade apresentada por Picel é resultado da pluralização indicada no Qal: pedir" $\rightarrow$ "mendigar”; "rir" $\rightarrow$ "zombar"; “quebrar” $\rightarrow$ “estraçalhar”; Joüon-Muraoka (1993, p.155) também identificam um

\footnotetext{
8 “... the question how the function of Piel in relation to other conjugations, notably Qal, should be defined still remains one of the major challenges facing Hebrew and Semitic linguistics. In the present state of our knowledge, we can only point to a number of fairly distinct meaning categories into which some verbs seem to fit. Others, an uncomfortably large number, still defy such categorization." (JOÜON-MURAOKA, 1993, p. 154 e155)

${ }^{9}$ LAMBDIN, 2003, p. 236.

${ }^{10}$ Segundo Joüon-Muraoka, "Tradicionally it has been considered intensive in meaning. It is to be doubted whether there is a direct link between this assumed function and the doubling of the second radical" (JOÜON-MURAOKA, 1993, p. 151 e 152).
} 
sentido plural, que envolve múltiplos sujeitos ou objetos, além de do "frequentativo", pois tem a ver com a frequência com que a ação é praticada: "contar" $\rightarrow$ "recontar";

b) Na opinião de Lambdin (2003, p. 236), o uso mais consistente do $\mathrm{Pi}^{\mathrm{c}}$ el é o factitivo ${ }^{11}$ que consiste na transformação de um verbo Qal estativo ou de sentido intransitivo em um verbo ativo transitivo: Qal: "estar são" $\rightarrow$ Picel: "sarar"

- Semelhante ao factitivo, esta derivação, se aplicada a uma raiz Qal transitiva, originará um verbo causativo 12 : Qal: “aprender" $\rightarrow \mathrm{Pi}^{\mathrm{c} e l}$ : “ensinar" (isto é, causar o aprendizado)

- De um verbo Qal transitivo ou intransitivo pode-se formar um Picel transitivo: Qal: “queimar" (tr. ou intr.) $\rightarrow \mathrm{Pi}^{\mathrm{c}} \mathrm{el}$ : “queimar" (tr.);

c) Joüon-Muraoka (1993, p. 155) apresentam um sentido declarativo-estimativo associado ao seu valor factitivo, uma vez que "denota a geração de um estado ou qualidade real e fisicamente, e a declarativa-estimativa faz isso mentalmente ou verbalmente"13: "declarar limpo", "declarar inocente", "declarar impuro";

d) Lambdin (2003, p. 237) classifica como denominativo os verbos que não têm um Qal correspondente ou que são semanticamente mais próximos de um substantivo ou adjetivo que de um verbo. Joüon-Muraoka (1993, p. 155) dizem ser a categoria desses verbos lexical e não gramatical, já que por trás de cada um deles há seguramente um nome: "falar" (de palavra), "dividir em três partes" ou "fazer pela terceira vez" (de três); "agir como padre";

e) Joüon-Muraoka (1993, p. 156) apontam um uso adverbial, raro, do $\mathrm{Pi}^{\mathrm{c}} \mathrm{el}$ : "agir perversamente"; "agir de maneira iníqua", "agir rapidamente”;

f) Há ainda um grupo de verbos não categorizados, pois sua origem não é clara: “desviar", "procurar", “despedir". ${ }^{14}$

\subsection{Pucal}

$\mathrm{Pu}^{\mathrm{c}}$ al é a contraparte passiva do $\mathrm{Pi}^{\mathrm{c}} \mathrm{el}$, que se forma por meio de alterações vocálicas. Tanto no perfectivo quanto no imperfectivo, a vogal da primeira sílaba é /u/, e a da segunda letra radical, /a/. Joüon-Muraoka (1993, p. 165) referem que, originalmente, o perfectivo tinha,

\footnotetext{
${ }^{11}$ From Lat. facere "to make." This is to be distinguished from the notion of "causative": "to make him holy" as against "to make him walk." (idem: 156).

${ }^{12}$ LAMBDIN, 2003, p. 236.

13 "denotes the generation of a state or quality actually and physically, the declarative-estimative does so mentally or verbally" (JOÜON-MURAOKA, 1993, p.155)

${ }^{14}$ LAMBDIN, 2003, p. 237.
} 
como segunda vogal, /i/, como o árabe, que foi suplantada por /a/, em analogia com o imperfectivo: quțtal/yuqțtal. Por conta dessa formação, os autores supracitados dizem ser esta conjugação também conhecida como "passiva interna": qițtel - "trucidar" $\rightarrow$ quțtal - "foi trucidado".

\subsection{Hip̄êil}

Esta forma é sempre ativa e pode ser causativa de uma forma básica Qal correspondente. A sua marca distintiva é um prefixo h-, que não aparece no imperfectivo; sendo assim, o que o identificará neste modo, diferindo-o do Qal, será o seu padrão vocálico apenas. É também conhecido como conjugação "H”, por causa do prefixo: Perfectivo: hiqț̂l - Imperfectivo: yaqț̂l $\rightarrow$ "fazer matar".

\section{Valores semânticos:}

a) O principal valor deste verbo é de causa:

Qal: "comer" $\rightarrow$ Hip̄icil: "fazer comer" = "alimentar"

Se a forma Qal for transitiva, o Hip $\bar{p}^{c}$ il será duplamente transitivo "com um objeto direto de 'causa' e um objeto direto da ideia verbal expressa pela raiz: "ele fez alguém ouvir algo"15.

b) Hip̄cil tem o sentido de conceder a coisa expressa pela raiz: "concordar com um pedido", "conceder algo pedido/solicitado". A forma Qal "pedir emprestado", tem um Hip̄cil "emprestar"; 16

c) Seu valor é estativo quando a ação continua com o sujeito, indicando um estado do mesmo. Pode ser intransitivo ou transitivo: Qal: "estar longe" $\rightarrow$ Hip̄ ${ }^{c}$ il: "afastar-se", "ser bom" $\rightarrow$ "fazer o bem/dar-se bem";

d) Às vezes, aplicar a forma ao Qal produz um modo de ação: Qal: “ser bom” Hip̄cil: "fazer (algo) bem";

e) Denominativo: orelha $\rightarrow$ "dar ouvidos, escutar", chuva $\rightarrow$ "produzir chuva, fazer chover". Joüon-Muraoka (1993, p. 163) fazem menção a um tipo de denominação que está ligada à ideia de tempo e lugar: "fazer algo de tarde"; "ir para a direita";

\footnotetext{
${ }^{15}$ LAMBDIN, 2003, p. 256.

${ }^{16}$ JOÜON-MURAOKA, 1993, p.163.
} 
f) Segundo Lambdin (2003, p. 259), como no $\mathrm{Pi}^{\mathrm{c} e l}$, alguns verbos não podem ser classificados por não se conhecerem as fontes das quais derivam: "aniquilar/destruir", "lançar/jogar fora".

\subsection{Hup ${ }^{-}$al}

Hup̄ al é a forma passiva de Hip̄̄îl, e, assim como ele, tem como prefixo um h-, que sofre queda no imperfectivo. É também chamada de conjugação "Hp", onde o p é de passivo: Hip̄îl: hiqț̂l "ele obrigou a matar" $\rightarrow$ Hup̄cal: huqțal "ele foi obrigado a matar".

\subsection{Hițpa ${ }^{\mathrm{c}}$ l}

Por ser reflexiva do $\mathrm{Pi}^{\mathrm{c}} \mathrm{el}$, Hiṭa ${ }^{\mathrm{c}} \mathrm{el}$, como ele, tem a segunda radical dobrada; porém com um elemento a mais: o prefixo hiț-: hitqatel.

Esta forma faz parte da chamada conjugação " $D$ ” (de duplicação) e é também conhecida como "HtD".

\section{Valores semânticos:}

a) O valor mais comum é que seja reflexivo de $\mathrm{Pi}^{\mathrm{c} e l: ~ " s a n t i f i c a r " ~} \rightarrow$ santificar-se;

b) Passivo: "ser esquecido";

c) Às vezes apresenta uma ideia de aparência: "mostrar-se falso"; "fingir-se doente"; "pretender ser rico";

d) Procura pela ação do verbo do qual deriva: "pedir por justiça", "pedir por misericórdia";

e) Denominativo: "remover/tirar o pecado de si mesmo".

Podemos resumir os aspectos descritos acima na seguinte tabela:

\begin{tabular}{|c|c|c|c|}
\hline VOZ & ATIVA & PASSIVA & REFLEXIVA \\
\hline Simples & 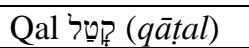 & 17 & Nip̄cal נִקְטַל (niqtal) \\
\hline Ação & ele matou & & $\begin{array}{l}\text { ele se matou } \\
\text { ele foi morto }\end{array}$ \\
\hline Intensiva $(?)^{18}$ & $\mathrm{Pi}^{\mathrm{cc}} \mathrm{el}$ קִטֵַ (qittel) & $\mathrm{Pu}^{\mathrm{cc}} \mathrm{al}$ ?ִ & 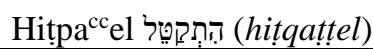 \\
\hline Ação & $\begin{array}{l}\text { ele matou } \\
\text { intensamente (?) }\end{array}$ & ele foi morto intensamente (?) & $\begin{array}{l}\text { ele se matou } \\
\text { intensamente (?) }\end{array}$ \\
\hline
\end{tabular}

${ }^{17}$ Segundo os autores, como as formas simples da passiva eram idênticas às formas perfectiva do $\mathrm{Pu}^{\mathrm{c}}$ al $($ qutal $(a)$ e imperfectiva do $\mathrm{Hop}^{\mathrm{c}}$ al (yuqtal $(u)$, os gramáticos antigos as consideraram como $\mathrm{Pu}^{\mathrm{c}} \mathrm{al}$ e Hop$\overline{\mathrm{c}}^{\mathrm{c}}$ al, respectivamente, e não como passivas de Qal.

${ }^{18}$ Conferir página 7 , a. 


\begin{tabular}{|c|c|c|}
\hline Causativa & 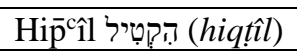 & 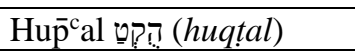 \\
\hline Ação & ele fez matar & ele foi obrigado a matar \\
\hline
\end{tabular}

Adaptada de Joüon-Muraoka (1993p. 124).

Além das formas listadas acima, o hebraico possui ainda um grupo que, mesmo no hebraico clássico, eram muito raras e que não foram aqui abordadas.

\section{O verbo trilítero derivado árabe: al-mazīd}

Como já foi dito, a maioria dos verbos árabes são trilíteros, isto é, apresenta três letras chamadas radicais. A partir do verbo trilítero primitivo, mujarrad (lit. despido, desnudado: primitivo), é possível formar mais quinze novas formas verbais chamadas mazìd (lit. “acrescido/aumentado"). Este acréscimo consiste na sufixação ou infixação de certos elementos à raiz verbal, e que implica alguma alteração no significado da forma primitiva.

As formas derivadas, nos livros ocidentais, são indicadas com numerais romanos: forma I, forma II..., porém os gramáticos árabes empregam o verbo فَ $f a^{c} a l a$ (ele fez) para ilustrar todas as formas possíveis de palavras derivadas existentes. A tabela abaixo ilustra as quinze formas verbais passíveis de serem formadas em árabe:

\begin{tabular}{|c|c|c|c|c|c|c|c|c|}
\hline I & فَعَلَ & $f a^{c} a l a$ & VI & تَفَاعَلَ & tafáa $\bar{a}^{c}$ ala & XI & إِفْعالَ & ${ }^{2} i^{c} \bar{a} l a$ \\
\hline II & فَعَّلَ & $f a^{c c} a l a$ & VII & إِنْفَعَلَ & 'infacala & XII & إِفْعَوْعَلَ & ${ }^{\prime}$ if $^{c} a w a^{c} l a$ \\
\hline III & فاعَلَ & $f \bar{a}^{c} a l a$ & VIII & إِفْتَعَلَ & iftac ala & XIII & إِفْوََّلَ & if ${ }^{c} a w w a l a$ \\
\hline IV & أَفْغَلَ & ${ }^{?} a f^{c} a l a$ & IX & إِفْعَلَّ & 'if alla & XIV & إِفْعَنْلَلَ & ?ifcanlala \\
\hline $\mathrm{V}$ & تَفَعَّلَ & tafa ${ }^{c c}$ ala & $X$ & إِنْتَفْعَلَ & 'istaf'ala & XV & إِفَْنْنَلَ & 'if'anlá \\
\hline
\end{tabular}

Como no capítulo anterior, dentre todas as formas existentes, trataremos somente das dez primeiras, pois são as mais produtivas. As cinco últimas são raras, sendo somente encontradas em poesia ou textos arcaicos.

\subsection{Forma I - facala}

$F a^{c} a l a$ é a forma simples ativa. Sua marca característica é a ausência de qualquer elemento mórfico além das letras radicais e seus padrões vocálicos, que, como já visto acima, para a primeira e última sílaba é /a/, e para a segunda letra radical pode ser qualquer uma das três vogais breves do sistema vocálico arábico: /a/, /i/ ou /u/: qatala - "ele matou". 


\subsection{Forma II - fa ${ }^{\mathrm{cc}}$ ala}

Os verbos da forma II apresentam dobramento da segunda letra da forma primitiva: qattala - "ele massacrou".

\section{Valores semânticos:}

a) Esta forma apresenta a ideia de fazer ou causar, isto é, é causativo-factitivo: I waqafa "pôr-se de pé, parar-se" $\rightarrow$ II waqqafa "pôr algo de pé, parar algo"

Como consequência do seu valor causativo, a forma II transforma o verbo primitivo intransitivo ou estativo em transitivo; se o verbo primitivo já for transitivo, torna-se bitransitivo:

estativo: "ser honrado" $\rightarrow$ transitivo: "honrar" (alguém)

intransitivo: "voltar" $\rightarrow$ transitivo: "devolver" (algo)

transitivo: "estudar" $\rightarrow$ bitransitivo: "ensinar" (algo a alguém);

b) Alguns verbos da forma II indicam uma intensidade maior ou uma repetição da ação da forma primitiva: kasara - quebrar $\rightarrow$ kassara - quebrar em pedaços; daraba - bater $\rightarrow$ darraba - bater fortemente;

d) Quando aplicada a alguns verbos intransitivos, atribui-lhes um valor declarativo-

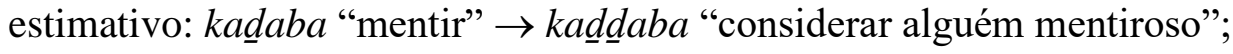

e) Essa forma pode ser aplicada a nomes para a formação de verbos: "celebrar uma festa" (de festa), "dar sobrenome" (de sobrenome).

\subsection{Forma III - fācala}

Esta forma apresenta um alongamento da vogal /a/ da primeira letra radical: qātala - "ele combateu".

\section{Valores semânticos:}

a) Frequentemente transmite a ideia de reciprocidade, de que o sujeito está fazendo ou tentando fazer algo com outro alguém. O próprio verbo árabe "tentar" ( hāwala) é deste paradigma. Como consequência desta característica, quase todos os verbos da forma III são transitivos: "encontrar-se com", "sentar-se com”.

Alguns verbos não apresentam ideia de reciprocidade, parecendo-se, em significado aos verbos primitivos: "viajar", "assistir/ver". 


\subsection{Forma IV - ?af'ala}

Esta forma tem um hamza /\%/ prefixado à raiz primitiva, e perde a vogal da primeira letra radical. Ao longo de toda a conjugação do imperfectivo, o hamza é elidido: 'aqtala - "expor à morte". 19

\section{Valores semânticos:}

a) Assim como os verbos da forma II, grande parte destes verbos tem um significado causativo-factitivo. Se o verbo primitivo for intransitivo, nesta forma, fica transitivo; e, se já for transitivo, fica bitransitivo: "ouvir" $\rightarrow$ "fazer alguém ouvir/contar algo a alguém"; "aparecer" $\rightarrow$ "fazer aparecer/mostrar".

- Quando o verbo for bitransitivo, é seguido por dois complementos no acusativo (dois objetos diretos): 'akramtu hasanan 'ikrāman kabīran (lit. honrei Hassan uma grande honra).

- Por causa de sua característica causativa, as formas II e IV assemelham-se muito em significado, e, em algumas raízes, as duas apresentam o mesmo valor semântico: Forma II /dahhala/ = Forma IV /'adhala/: "fazer entrar = introduzir".

b) Wright $(1862$, p. 33) faz referência a um tipo especial de denominativo da forma que indica movimento para um lugar, entrada em um período de tempo ou uma ação ou estado ocorrendo durante um tempo: "ir para o Iêmen”, "ser ou fazer algo de manhã/de tarde".

c) Alguns verbos têm uma falsa aparência de estativos quando traduzidos: "morar" ('aqāma lit. fazer um lugar para ficar), "ser velho", "ser possível”. Isto acontece "em parte porque o objeto foi, no curso do tempo, omitido por causa da brevidade [...], e em parte porque os árabes veem ação onde nós vemos estado. ${ }^{20}$

\subsection{Forma V - tafa ${ }^{\mathrm{cc}}$ ala}

Esta forma é derivada da II. Apresenta a prefixação da letra $\langle t\rangle$, e o dobramento da segunda letra radical: taqattala "dedicar-se intensamente a, matar-se de". ${ }^{21}$

\footnotetext{
${ }^{19}$ CORRIENTE, 1991, p. 208.

${ }^{20}$ partly because the object has been in the course of time omitted for the sake of brevity, and [...] partly because the Arabs often regard as an act that which we view as a state (WRIGHT, 1862, p. 33).

${ }^{21}$ Corriente, 1991, p. 208.
} 


\section{Valores semânticos:}

a) Muitos verbos são reflexivos da II e, às vezes, têm um sentido passivo: Forma II "lembrar" $\rightarrow$ Forma V "lembrar-se de"

b) Quando derivados de nomes, se traduzem por ser/tornar-se ou pretender ser como o nome do qual derivam: "denominar-se profeta" (de profeta), "tornar egípcio" (de Egito).

\subsection{Forma VI - tafācala}

Esta forma é derivada da III. Apresenta a prefixação da letra $\langle\mathrm{t}\rangle$, e o alongamento da vogal da primeira letra radical /ā/: taqūtala "combater-se".

\section{Valores semânticos:}

a) Os verbos deste paradigma costumam apresentar um sentido reflexivo e de reciprocidade, como a forma III da qual deriva, porém, aqui, o objeto da ação se torna sujeito, que, geralmente, é composto por duas ou mais palavras, ou duas ou mais palavras no plural ou dual. Uma palavra com sentido coletivo também pode ser o sujeito: "eles dois se corresponderam (um com o outro)", "Nagib e Nádia encontramse (um com o outro) todo dia".

b) Verbos desta forma indicam uma característica passageira ou permanente, que traduzimos por um adjetivo acompanhado dos verbos ser ou estar: "ser preguiçoso".

c) Assim como a forma $\mathrm{V}$, também pode ser empregada para simular um estado ou característica, dando uma ideia de aparência do nome ao qual está relacionado. O verbo fingir /tad âhara/ é deste paradigma: "fingir-se de ignorante", "fingir-se de enfermo", "fingir lentidão".

d) Ryding (2005, p. 543) menciona uma característica gradativa dessa forma de indicar o processo em desenvolvimento: "mudar", "diminuir".

\subsection{FormaVII - 'infacala}

Esta forma é derivada da I e é formada com a prefixação de 'in-. Como em todos os demais casos, o hamza inicial é instável e cai no imperfectivo: 'inqatala $(\varnothing)$.

\section{Valores semânticos:}


a) Os verbos da forma VII dão à forma primeira um sentido reflexivo ou passivo: Forma I “descobrir" $\rightarrow$ Forma VIII "descobrir-se";

b) Associado ao sentido passivo, está o resultativo. Ryding lembra que o termo árabe para passivo/reflexivo é $m u t ̦ a \bar{w} w i$ (obediente), e exemplifica: “eu abri (na Forma I) a porta e ela se abriu (na Forma VII)". Decorrente dessa "obediência", também encontramos os verbos que indicam a ideia do consentimento de alguém para que a ação se exerça sobre ele: "deixar-se enganar", "deixar-se levar/conduzir".

\subsection{Forma VIII - 'iftacala}

A forma VIII é a voz reflexiva ou média da I. Tem o prefixo hamza /₹/ e o morfema 〈t> entre as segunda e terceira letras radicais. Como as outras formas com hamza incial, no imperfectivo, ele é elidido: 'iqtatala: "combater-se".

\section{Valores semânticos:}

a) A forma VIII é a mais complexa quanto à significação. Apesar de ser derivada da I, muitos verbos não apresentam, aparentemente, nenhuma relação semântica com a sua raiz: Forma I ferir $\rightarrow$ Forma VIII realizar/conseguir

b) Por outro lado, muitas vezes, o valor da forma VIII é idêntico ao da I, e para muitos verbos a mesma palavra serve para traduzir as duas formas: basima = 'ibtasama $\rightarrow$ (so)rir

c) Alguns verbos são reflexivos ou passivos da I: "ocupar" $\rightarrow$ "ocupar-se", "separar/dividir" $\rightarrow$ "separar-se/dividir-se", "expulsar" $\rightarrow$ "ser expulso".

d) O valor de reciprocidade das formas III e VI também estão presentes em alguns verbos: "combater com”, “disputar com”, "lutar com”.

\subsection{Forma IX - 'if ${ }^{\mathrm{c}}$ alla}

A forma IX é derivada da I, e, das dez, é a menos produtiva. A estrutura de sua forma apresenta o prefixo hamza /\%/, e o dobramento da última letra radical: 'iqtalla (Ø).

\section{Valor semântico:}

a) O emprego da forma IX é raro, pois ele é restrito a verbos que indicam cores e características físicas: "ser/tornar-se branco", "esverdear-se/tornar-se verde", "ser vesgo". 


\subsection{Forma X - 'istaf ${ }^{\mathrm{c}}$ ala}

A forma X é muito comum e tem o prefixo 'ista-: 'istaqtala: "buscar a morte", "lançar-se ao perigo".22

\section{Valores semânticos:}

a) Geralmente, indica pedido ou desejo da ação ou estado do verbo do qual deriva: "pedir permissão", "pedir perdão", "procurar proteção".

b) Quando deriva de verbo intransitivo que designa estado, é comum apresentar um valor estimativo, de 'considerar como’: "ser fácil/plano" $\rightarrow$ "considerar fácil/plano"; "ser grande/importante" $\rightarrow$ "considerar grande/importante".

O valor estimativo apresentado pela forma, muitas vezes, indica que alguém considera que algo é para seu benefício próprio: “apropriar-se/monopolizar”, “merecer”.

c) Essa forma pode ser derivada tanto da forma I, quanto da IV quando tem um sentido causativo ou reflexivo: Forma I "chorar" $\rightarrow$ Forma X "fazer chorar" (causativo); Forma IV "pôr de pé, levantar" $\rightarrow$ Forma X "levantar-se/pôr-se de pé (reflexivo)

d) Alguns verbos derivados de nomes indicam mudança de estado ou nomeação: "tornarse homem", "nomear alguém como ministro".

\section{Análise contrastiva entre os binyanim hebraicos e o verbo mazīo árabe}

Antes de procedermos à análise dos dados, alguns pontos devem ser esclarecidos. $\mathrm{O}$ primeiro é que não foi objetivo deste trabalho fazer uma descrição detalhada, no aspecto morfológico, das formas verbais aqui estudadas. Desse modo, não nos detivemos no estudo das vogais. Nas duas línguas, a aplicação dos diferentes padrões às raízes provoca alteração nos movimentos vocálicos, além da característica especial de certos fonemas que, no caso do hebraico, ainda produz mudanças vocálicas maiores. Também não explicitamos a influência dos fonemas formativos nos diversos tipos de raízes primitivas ao longo de sua flexão, que

\footnotetext{
${ }^{22}$ CORRIENTE, 1991, p. 208.
} 
provocam assimilações, quedas.... Por fim, não pretendemos também esgotar todas as possibilidades de significados que essas formas resultantes podem encerrar.

O ponto de partida de nossa análise se deu a partir do hebraico. Analisaram-se os valores semânticos apontados nos autores pesquisados e procurou-se identificar os mesmos padrões na língua árabe.

A forma I, Qal e $f a^{c} a l a$, não são contempladas nas análises a seguir, por não terem sido aqui estudas, visto a multiplicidade de seus valores semânticos.

\subsection{Nip̄ecal}

Nip ${ }^{-}$al tem como principal característica morfológica a prefixação do elemento $/ \mathrm{n} /$. A forma VII árabe se assemelha a ela e apresenta este mesmo elemento em seu prefixo. Comparados os dois verbos, observamos o que segue na tabela abaixo:

\begin{tabular}{l|l|l|}
\multicolumn{1}{c|}{} & \multicolumn{1}{c|}{ nip $^{\mathbf{c}}$ al } & \multicolumn{1}{c}{ 'infa $^{\mathbf{c}} \mathbf{a l a}$} \\
\hline Morfologia & Prefixo ni- & Prefixo 'in- \\
\hline \multirow{4}{*}{ Valores semânticos } & a) reflexivo & a) reflexivo \\
\cline { 2 - 3 } & b) passivo & b) passivo \\
\cline { 2 - 3 } & c) resultativo & c) resultativo \\
\cline { 2 - 3 } & d) voz média & d) voz média \\
\cline { 2 - 3 } & e) recíproco & e) $\emptyset$ \\
\hline & f) denominativo & f) (?) \\
\hline
\end{tabular}

Dos sete valores de $\mathrm{Ni}^{\mathrm{c}} \mathrm{al}$, encontramos cinco correspondentes em árabe na forma

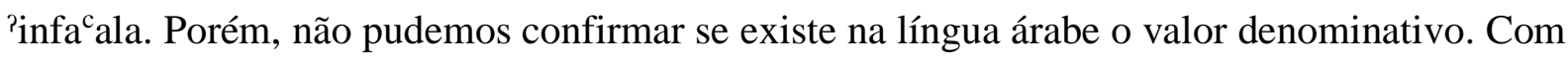
relação ao valor "reciprocidade", Wright (1862, p. 37) assevera "Deve-se observar, no entanto, [...] que ele nunca assume a significação recíproca". ${ }^{23}$

As formas árabes que indicam valor recíproco são as Formas III, VI, VIII; e denominativo são as Formas II, V, VI e X.

\subsection{Picel}

${ }^{23}$ It must be remarked, however [...] that it never assumes the reciprocal signification. (WRIGHT, 1862:37) 
A principal característica desse verbo é a duplicação da segunda letra radical. Em árabe este mesmo processo ocorre com a forma II, $\mathrm{fa}^{\mathrm{cc}}$ ala.

\begin{tabular}{c|c|c|}
\multicolumn{1}{c|}{} & pi $^{\mathbf{c c}} \mathbf{e l}$ & fa $^{\mathbf{c c}} \mathbf{a l a}$ \\
\hline \multirow{2}{*}{ Morfologia } & duplicação da consoante medial & duplicação da consoante medial \\
\hline \multirow{4}{*}{ Valores semânticos } & a) frequentativo ou plural & a) intensificador \\
\cline { 2 - 3 } & b) causativo-factitivo & b) causativo-factitivo \\
\cline { 2 - 3 } & c) estimativo & c) estimativo \\
\cline { 2 - 3 } & d) denominativo & d) denominativo \\
\cline { 2 - 3 } & e) adverbial & e) (?) \\
\hline
\end{tabular}

Das características semânticas que a forma duplicada dos verbos hebraicos apresenta, quatro foram atestadas para o árabe. Não conseguimos, com nossos exemplos, confirmar se existe para esta forma, no árabe, o sentido adverbial. Com relação a verbos que ainda não foram categorizados, observamos em nossos estudos que eles existem não apenas na forma II, mas também em outras. Embora, no hebraico, os autores aqui estudados (Lambdin ${ }^{24}$ e JoüonMuraoka) ${ }^{25}$ discutam o valor "intensivo" desta forma e apontem outros sentidos (plural, frequentativo), o resultado é o mesmo nas duas línguas. Nos trabalhos analisados para esta pesquisa sobre o árabe, não encontramos discussão quanto ao assunto, e Wright (1862, p. 29) afirma:

A significação concorda com a forma a respeito de ser intensiva ou extensiva. Originalmente ele implicava que um ato era feito com "grande violência" (intensivo), ou que durava longo tempo (temporalmente extensivo) ou um número de pessoas (numericamente extensivo) ou repetitivo (iterativo frequentativo). ${ }^{26}$

\subsection{Pu'al}

\footnotetext{
24 "Pode então ter matiz de intensidade, embora esta força "intensiva", na maioria dos casos, seja difícil de discernir" (LAMBDIN, 2003, p. 237)

${ }^{25} \mathrm{Cf}$. nota 9.

${ }^{26}$ The signification agrees with the form in respect of being intensive or extensive. Originally it implies that na act is done with great violence (intensive), or during a long time (temporally extensive), or to a number of persons (numerically extensive), or repeatedly (iterative or frequentative) (WRIGHT, 1862, p. 29).
} 
Apesar de os verbos mazīd do árabe terem vários paradigmas que indicam a passividade, nenhum deles se enquadra no quesito "contraparte passiva da forma II". Isto é, a forma II tem voz passiva, que se dá por meio de alterações vocálicas, como a hebraica, porém não recebe nenhuma denominação especial.

\subsection{Hip̄îl}

O verbo Hip̄ềl tem como marca distintiva um prefixo hi-, que no imperfectivo é elidido, sendo assim, apenas identificado pelos padrões vocálicos diferentes do da raiz de base. A forma árabe que se encaixa nestes moldes é a IV. Sua marca característica é o prefixo hamza? que também é elidido no imperfectivo, ficando a cargo do movimento vocálico diferenciar a forma derivada da sua correspondente primitiva.

\begin{tabular}{|c|c|c|}
\hline & hip̄îil & 'iffala \\
\hline Morfologia & Prefixo hi- & Prefixo 'i- \\
\hline \multirow{6}{*}{ Valores semânticos } & a) causativo & a) causativo-factitivo \\
\hline & b) permissivo & b) (?) \\
\hline & c) estativo & c) estativo \\
\hline & d) adverbial & d) (?) \\
\hline & e) denominativo & e) denominativo \\
\hline & f) não categorizados & f) (?) \\
\hline
\end{tabular}

Percebemos pela morfologia e pelos aspectos semânticos que as duas formas se correspondem, embora alguns valores apresentados pelos estudiosos do hebraico não tenham sido comprovados para o árabe nos autores aqui consultados.

\subsection{Hup ${ }^{-} a l$}

Esta forma é a passiva correspondente ao Hip̄ê̂l, e, mais uma vez, a única diferença da forma ativa são os movimentos vocálicos. Nenhuma das dez derivações árabes se encaixa neste padrão.

\subsection{Hitp 'ael $^{\text {a }}$}


Hitp $^{c}$ ael é a forma mais extensa das construções verbais hebraicas. Em árabe, a forma mais extensa é ${ }^{P}$ istaf ${ }^{\mathrm{c}}$ ala. Embora o único elemento em comum seja o morfema $\langle\mathrm{t}\rangle$, percebemos muito em comum entre as duas formas.

\begin{tabular}{c|l|l|}
\multicolumn{1}{|c|}{ hitp $^{\mathbf{c}} \mathbf{a e l}$} & \multicolumn{1}{c|}{ 'istaf $^{\mathbf{c}}$ ala } \\
\hline Morfologia & Prefixo hit- & Prefixo 'ista- \\
\hline \multirow{4}{*}{\begin{tabular}{c}
\multirow{2}{*}{ Valores } \\
semânticos
\end{tabular}} & a) reflexivo & a) reflexivo \\
\cline { 2 - 3 } & b) passivo & b) causativo \\
\cline { 2 - 3 } & c) ideia de aparência & c) estimativo \\
\cline { 2 - 3 } & d) procura pela ação verbal & d) procura pela ação verbal \\
\cline { 2 - 3 } & e) denominativo & e) denominativo \\
\hline
\end{tabular}

Os valores apresentados pelas duas formas se equivalem mais do que se diferenciam. $\mathrm{O}$ verbo hebraico apresenta passivas deste padrão e o árabe, segundo os autores, não.

Em contrapartida, a forma $\mathrm{X}$ árabe apresenta um valor causativo que não conseguimos aqui constatar para este padrão do hebraico. A ideia de aparência do Hitp ${ }^{c}$ ael, pode ser equiparada, grosso modo, com o valor estimativo da forma árabe: fingir-se algo x considerar algo.

Percebemos, pela análise das tabelas contrastivas, que cada verbo hebraico apresenta mais valores semânticos que os árabes. Isso se deve, talvez, pelo menor número de construções, se comparado ao árabe. De fato, só pudemos constatar uma equivalência mais efetiva com relação a quatro formas. No entanto, todos os aspectos apresentados pelas formas hebraicas são encontrados nas diversas formas árabes que não encontraram uma correspondência morfológica com os binyanim hebraicos.

Apenas um paradigma árabe, muito específico, não encontrou nenhum correspondente dentre as construções hebraicas: a forma IX, que indica cores e características físicas.

Podemos finalizar a nossa análise contrastiva, resumindo num quadro:

\begin{tabular}{|c|c|}
\hline Hebraico & Árabe \\
\hline Qal - Pa ${ }^{\mathrm{c}} \mathrm{al}$ & $\mathrm{fa}^{\mathrm{c}} \mathrm{ala}$ \\
\hline $\mathrm{Nip}^{\mathrm{c}} \mathrm{al}$ & infacala \\
\hline $\mathrm{Pu}^{\mathrm{c}} \mathrm{al}$ & $\varnothing$ \\
\hline $\mathrm{Pi}^{\mathrm{c}} \mathrm{el}$ & $\mathrm{fa}^{\mathrm{cc}}$ ala \\
\hline Hip $^{-c}$ il & 'if'ala \\
\hline Hup ${ }^{c}$ al & $\varnothing$ \\
\hline Hița ${ }^{\mathrm{c}} \mathrm{el}$ & 'istaf ${ }^{c}$ ala \\
\hline
\end{tabular}




\section{Algumas considerações finais}

Observamos, nos exemplos das duas línguas estudadas, que a formação dos verbos, a partir da raiz trilítera simples, se dá por meio de processos morfológicos extremamente previsíveis e regulares com o recurso de prefixação, infixação, dobramento de letras e alteração dos padrões vocálicos da raiz primitiva. $\mathrm{O}$ hebraico possui sete, e o árabe dez paradigmas nos quais todos os verbos das línguas devem se encaixar.

Embora os processos morfológicos atuantes na criação desses verbos sejam bastante regulares, não se pode dizer o mesmo quanto aos valores semânticos, que em várias ocasiões se apresentam como um desafio para uma classificação eficaz. Geralmente, cada forma de derivação está associada a algum significado específico, como tentar fazer a ação expressa pelo verbo do qual deriva, tornar o verbo passivo, fazer algo com alguém, etc., porém este princípio não se observa o tempo todo, e o significado de cada formação deve ser verificado no dicionário, pois alguns conceitos podem não corresponder ao significado do paradigma, ou podem ter sido alterados com o uso.

Ainda que, a princípio, todas as formas primitivas possam aceitar todas as derivações, nem todas existem para todas as raízes, e, geralmente, uma forma primitiva tem uma ou duas derivadas pelo menos. O próprio verbo /fa ${ }^{\mathrm{c}}$ ala/, usado como modelo para formação de todas as possibilidades de derivação árabe, não possui todas as formas ${ }^{27}$.

Apesar de vários autores ocidentais observarem em seus trabalhos o quanto estes padrões auxiliam na obtenção de vocabulário, os estudos modernos do hebraico e do árabe têm mostrado o quanto ele pode ser complexo, já que algumas formas esperadas não se evidenciam e outras inesperadas emergem. No entanto, mesmo com todas as dificuldades, esse sistema de formação de palavras ainda permanece um bom ponto de partida para se começar a compreender essas línguas semíticas.

\section{Referências bibliográficas}

AMMAR, S., DICHY J. LesVerbs Arabes. Collection Bescherelle. Paris: Hatier, 1999.

BARTELT, Andrew H. Gramática do hebraico bíblico: fundamentos. Canoas: Ed. ULBRA, 2006.

CORRIENTE, F. Diccionario arabe - español. Barcelona: Editorial Herder, 1991.

\footnotetext{
${ }^{27} \mathrm{O}$ verbo $f a^{c}$ ala ${ }^{2}$ apresenta apenas as formas II, VI,VII e VIII.
} 
CORTÉS. Julio. Diccionario de árabe culto moderno: árabe-espanhol. Madrid: Editorial Gredos, 1996.

COWAN, D. Gramática do árabe moderno. São Paulo: Editora Globo, 2006.

GOMES, Elias M. Mil e um verbos árabes: uma proposta lexicográfica. Dissertação de Mestrado (Língua, Literatura e Cultura). Faculdade de Letras - Universidade de São Paulo, 2011.

HAYWOOD, J. A.; NAHMAD, H. M. A New Arabic Grammar of the Written Language. London: Lund Humphries, 1965.

HETZRON, Robert. The Semitic Languages. London and New York: Routledge, 1997.

HOLES, Clive. Modern Arabic: structures, functions, and varieties. Washington D.C.: Georgetown University Press, 2004

JOÜON, P; MURAOKA, T. A. Grammar of Biblical Hebrew. Roma: Ed. Pontificio Istituto Biblico, 1993.

KELLEY, Page H. Hebraico Bíblico: uma gramática introdutória. $7^{\text {a }}$ edição. São Leopoldo: Editora Sinodal, 1998.

LAMBDIN, Thomas. Gramática do hebraico bíblico. São Paulo: Paulus, 2003.

RYDING, Karin C. A Reference Grammar of Modern Standard Arabic. New York: Cambridge University Press, 2005.

SABBAGH. A.N. Dicionário árabe-português. Rio de Janeiro: Fundação Biblioteca Nacional e Almádena, 2011.

Dicionário português-árabe. Beirute: Librarie du Liban, 2004.

WILLIAM, Chomsky. How the Study of Hebrew Grammar Began and Developed. In: The Jewish Quarterly Review, New Series, Vol. 35, No. 3, p. 281-301 Published by: University of Pennsylvania Press Stable, Jan. 1945.

WRIGHT, W. A. Grammar of the Arabic Language. London: Williams and Norgate, 1862. YATES, Kyle M. Nociones essenciales del hebreo bíblico. El Paso: Casa Bautista de Publicaciones, 1984. 